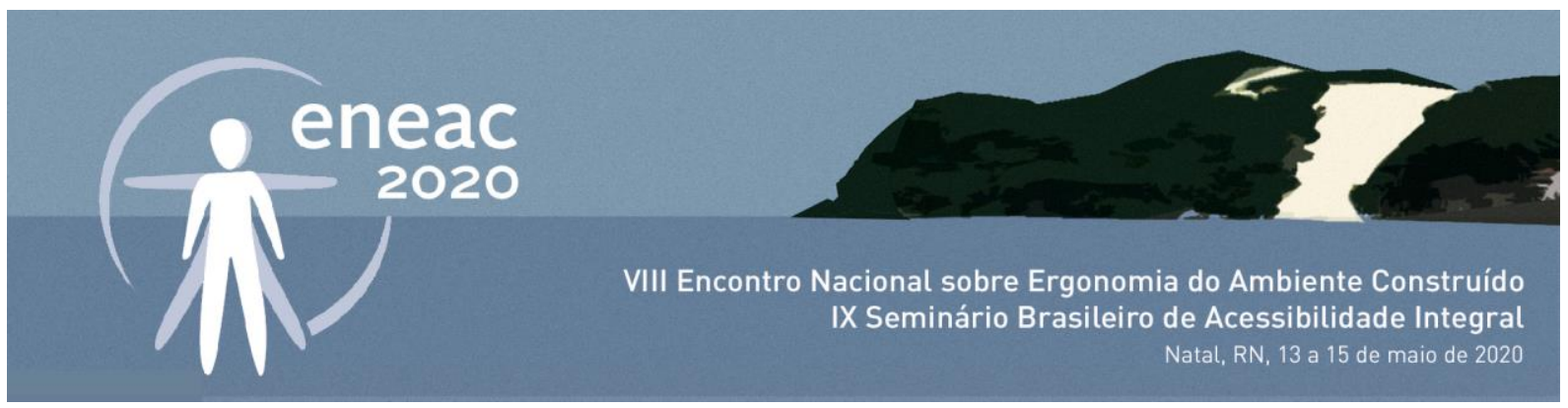

\title{
Casa de Apoio aos Pacientes em Tratamento: Estudo de Caso na Cidade do Recife-PE
}

\author{
Support House for Patients in Treatment: Case Study in Recife-PE
}

\author{
CHRISTIANNE SOARES FALCÃO \\ Doutora em Design, Universidade Católica de Pernambuco.
}

christiannefalcao.arq@gmail.com

RAMANA RODRIGUES MORAES

Arquiteta e Urbanista pela Universidade Católica de Pernambuco

\section{RESUMO}

O artigo consta na avaliação do ambiente construído de uma casa de apoio para pessoas que estão submetidas ao tratamento de saúde fora de sua cidade domicílio, situada na cidade do Recife-PE. A proposta que conduz a análise é a de traçar diretrizes para a projetação de espaços acolhedores, ressaltando a influência do espaço na saúde dando comodidade aos que precisam de um tratamento digno e humanizado. Para o cumprimento do objetivo proposto, as seguintes etapas foram seguidas: (1) Revisão de literatura sobre as casas de saúde e o tratamento fora de domicílio; (2) Pesquisa de campo com base na avaliação de desempenho e (3) Elaboração de diretrizes projetuais.

PALAVRAS-CHAVE: Ergonomia do Ambiente Construído, Humanização, Tratamento fora do domicílio

\section{ABSTRACT}

The aim of this paper is to evaluate the built environment of a support house for people who are taking health treatment outside their home town; it is located in Recife-PE. The analysis proposal is to outline guidelines for the design of welcoming spaces, emphasizing the space influence on health, giving comfort to those who need a dignified and humanized treatment. In order to achieve the proposed goal, the following steps were followed: (1) Literature review about nursing homes and treatment away from home; (2) Field research based on performance evaluation; and (3) Project development guidelines.

KEYWORDS: Built Environment Ergonomics, Humanization, Treatment outside the home 


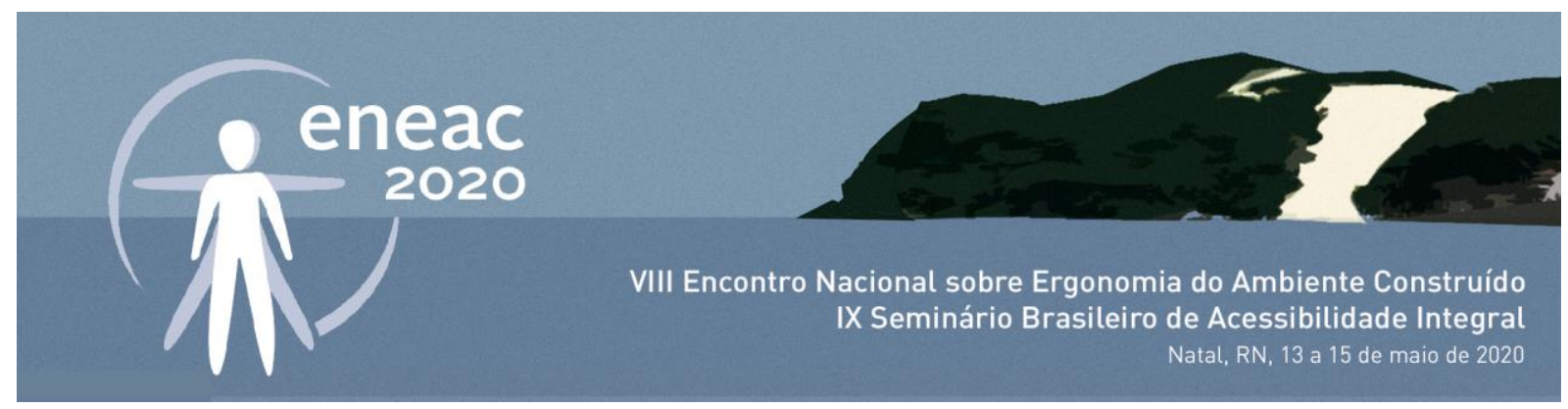

\section{INTRODUÇÃO}

Indivíduos que sofrem de doenças não tratáveis em seu município e precisam de tratamento longe de casa vivenciam uma situação de maior vulnerabilidade emocional e/ou física de estar em um local diferente, provoca nos usuários inquietação diante da probabilidade de não se adaptarem ao lar provisório. Este sentimento reflete a aflição dos que precisam passar por tal situação, sendo necessária a integração destes usuários ao meio, evitando a diferença do espaço ao seu modo de vida (FERREIRA et al, 2015).

Para explorar os benefícios desta moradia, poderá se fazer que cada paciente e acompanhantes desvendam o significado de conviver em grupo e interagindo entre si, para que fiquem em paz, união, e que possam compreender como a qualificação dessas instituições podem ter influência no seu tratamento. Uma rede de apoio deve conceder aos seus pacientes o auxílio instrumental e emocional. $\mathrm{O}$ instrumental é o financeiro, já o emocional deve propiciar a empatia, o zelo ao próximo e a boa acolhida (SOLIS; FUÃO, 2014).

A relevância desse estudo surge devido às transformações ocorridas durante o processo de cuidados a uma pessoa em tratamento distante de casa, salientando outros aspectos arquitetônicos que beneficiam o indivíduo como a ergonomia, a acessibilidade e o conforto ambiental.

As casas de apoio devem configurar-se como um ambiente familiar, diferente de alguns hospitais e aproximando-se do contexto doméstico, e ter a função de cuidar dos que nela se encontram, proporcionando bem-estar físico e emocional, além de dispor de assistência profissional que possibilite os cuidados fundamentais com os doentes no ambiente da casa (FERREIRA et al. 2015).

Desse modo, criar na vida dos pacientes durante seu processo terapêutico o estímulo físico proporcionando através da influência da luz, da cor, da forma, da textura, do som, do aroma, ameniza assim, a convivência dos que realizam tratamento longe de sua cidade.

\section{Casa de Apoio ao Paciente em Tratamento}

Conforme aponta o Ministério da Saúde (BRASIL, 2010), conviver com doenças graves e/ou incuráveis no lar é uma realidade vivenciada por muitas famílias. Deve-se lembrar que estas doenças são consideradas a causa de muitas mortes na população brasileira. Tal realidade acarreta uma reorganização social, sobretudo no que diz respeito ao apoio necessário oferecido aos familiares e pessoas que vivenciam diretamente essas doenças.

Contudo, os tratamentos são considerados de alta complexidade e carecem de recursos tecnológico e científico para sua realização. Tal característica limita o número de hospitais e clínicas que dispõem da infraestrutura necessária para tais procedimentos, restrito às cidades de grande porte. Neste sentido, pacientes de municípios pequenos, ao iniciarem sua luta contra essas doenças se deparam com mais uma barreira, a falta de acesso para o tratamento. Assim, esses indivíduos convivem com a necessidade de locomoção frequente até os centros especializados, o que dificulta ainda mais o enfrentamento da doença, por ocasionar desgaste físico, financeiro e emocional (FERREIRA et al., 2015).

Essa situação é agravada pelos efeitos colaterais decorrentes dos procedimentos, que podem provocar limitações, exigindo que os pacientes residam na cidade onde realizam o tratamento. Para isso, estes pacientes necessitam de um local de permanência, o que nem sempre é encontrado com 


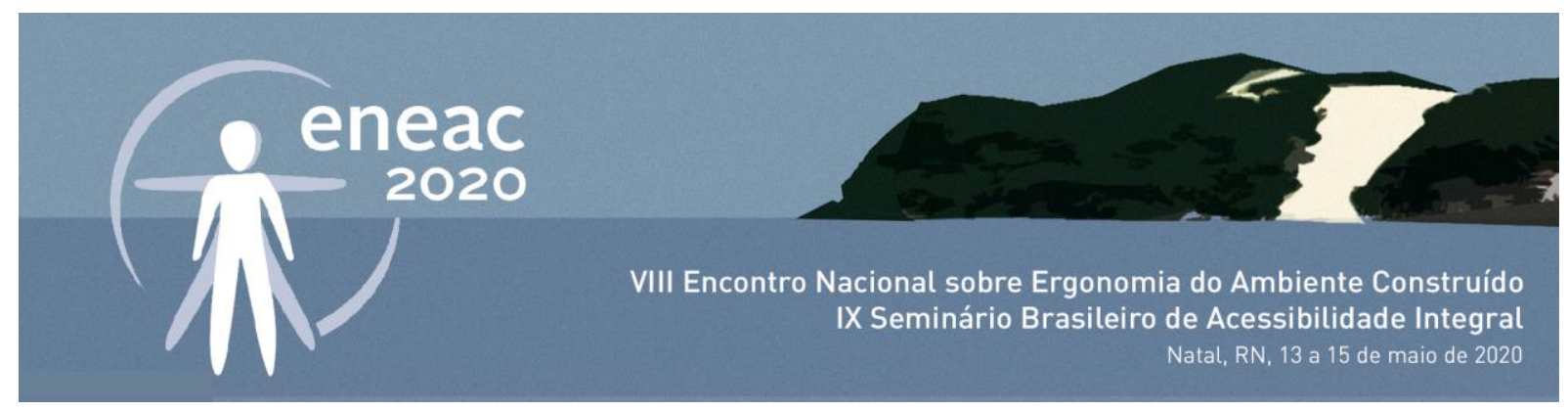

facilidade já que geralmente, o paciente e a famíliar não possuem condições de alugar uma moradia temporária ou têm algum familiar que possa os amparar. Sendo assim, houve a urgência designada por lei por parte dos representantes dos municípios de origem, de disponibillizar um local que abrigasse, acolhesse e suprisse as necessidades destes indivíduos nessa fase sensível e difícil que estão vivenciando. Com isso surgiram as casas de apoio, voltadas a oferecer assistência e cuidado a essas pessoas (BRASIL, 1999).

Na cidade do Recife, são localizadas várias destas casas de apoio pertecentes aos municípios do interior de Pernambuco. A maioria dos pacientes que precisam permanecer nestas casas, são aqueles que fazem tratamentos de quimioterapia e radioterapia, estes são procedimentos dolorosos e agressivos, além de serem de alta complexidade, limitando as instituições que fazem esses procedimentos, o que gera a necessidade de deslocamento desses indivíduos para os centros de especialização concentrados nas grandes cidades. Neste sentido, é de suma importância concender um espaço adequado para que os pacientes deem continuidade aos seus tratamentos (MELO; SAMPAIO, 2013).

Esta é uma realidade enfrentada pelos pacientes vindos de Araripina (PE), cuja casa de apoio é objeto de estudo deste artigo. Além de enfrentarem o desgaste físico e mental acarretado por viagens de longa duração, não possuem condições de custear uma hospedagem e muitas vezes nem conhecem a cidade na qual estão fazendo seus tratamentos. São pacientes de doenças graves que muitas vezes precisam ficar um período longo em Recife.

Desta maneira, por meio de visitas ao local e entrevistas com profissionais responsáveis pela casa de apoio, nota-se a grande demanda de indivíduos que precisam desse benefício, chegando a um quantitativo mensal de 540/560 pessoas em média. A principal problemática identificada na casa corresponde a falta de planejamento do espaço físico para receber os pacientes e seus familiares. A casa alugada não oferece condições físicas adequadas, visto que não foi projetada para este fim e sofreu adaptações, nem sempre bem-sucedidas, apresentando diversos problemas de conforto ambiental, fluxos, layout e dimensionamento.

\section{PROCEDIMENTOS METODOLÓGICOS}

Para atendimento ao objetivo deste estudo, que consiste em inserir os conceitos da arquitetura e da ergonomia na avaliação do ambiente construído das casas de apoio aos pacientes em tratamento, foi realizada como primeira etapa uma revisão de literatura sobre as casas de apoio e seu papel na sociedade atual. Na segunda etapa foi realizada uma avaliação do ambiente construído com base nos conceitos abordados em Falcão e Soares (2011) e Gomes, Felipe e Falcão (2017), a partir de uma pesquisa de campo na atual Casa de Apoio de Araripina.

A realidade vivenciada pelos pacientes foi investigada através de entrevistas e vivência com os pacientes e acompanhantes, no objetivo de enteder as atividades e a dinâmica da casa, assim como saber suas perspectivas sobre como deve ser um espaço de acolhimento, auxiliando na elaboração de diretrizes projetuais para promover a saúde, o conforto e a segurança dos pacientes em tratamento. 


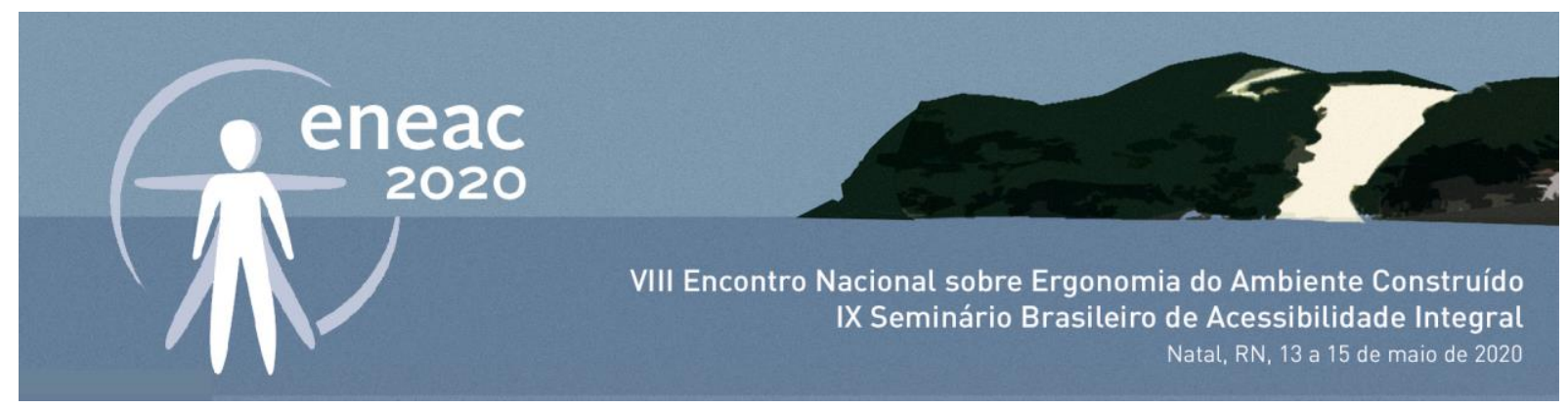

\section{Estudo de Campo}

Para a avaliação do ambiente construído da Casa de Apoio de Araripina (PE) foi utilizado um conjunto de métodos e técnicas que levam em consideração não somente o ponto de vista do avaliador, mas o bem-estar dos usuários, proporcionando análises completas e coesas sobre os elementos positivos e negativos encontrados no ambiente que auxiliarão na elaboração das diretrizes de projeto. Nesta perspectiva, o projeto participativo preocupa-se com a compreensão das necessidades físicas e funcionais do usuário, como também sua percepção em relação ao ambiente (GOMES; FELIPE; FALCÃO, 2017). Com base nestes fatores, a avaliação realizada seguiu as seguintes etapas: 1 . Análise da configuração do ambiente construído; 2 . Análise da Tarefa; 3. Análise da percepção do usuário; 4. Diagnóstico e 5. Diretrizes projetuais.

\section{Definição do Objeto de Estudo}

O município de Araripina está localizado no Estado de Pernambuco, no sertão do Araripe, a uma distância de $683 \mathrm{~km}$ da capital Recife. Devido a falta de recusos especializados na cidade, seus habitantes precisam deslocar-se para a capital para realizar tratamentos de alta complexidade. Diante disso, a casa de apoio recebe os usuários para que não precisem voltar para suas residências durante o período de tratamento. Sem a sua existência, a maioria dos pacientes não teriam como realizá-lo por não possuírem condições financeiras.

A atual casa de apoio de Araripina encontra-se no grande polo de centros de saúde conhecido como Ilha do Leite na região central do Recife, onde estão localizados alguns dos maiores hospitais do estado de Pernambuco, várias clínicas médicas e escritórios empresariais (Figura 1A). Além de ser um importante eixo de articulação urbana o que para os pacientes que não conhecem a cidade é de suma importância pois possuem facilidade de locomoção.

A edificação possui nove quartos (quatro se encontram no térreo e cinco no 10 pavimento), sete banheiros (quatro localizados no térreo e três no 1 o pavimento), uma cozinha, uma sala integrada a recepção e uma área externa que possui dois sofás e algumas cadeiras, além de não haver nenhuma acessiblidade no deslocamento para os cômodos, constituída apenas de uma escada de conexão do térreo ao primeiro pavimento e de grande quantidade de desníveis no ambiente. Lembrando que a maioria dos pacientes se encontram em estado debilitado e não possuem condições de vencer dificuldades de locomoção no ambiente ao qual estão estabelecidos.

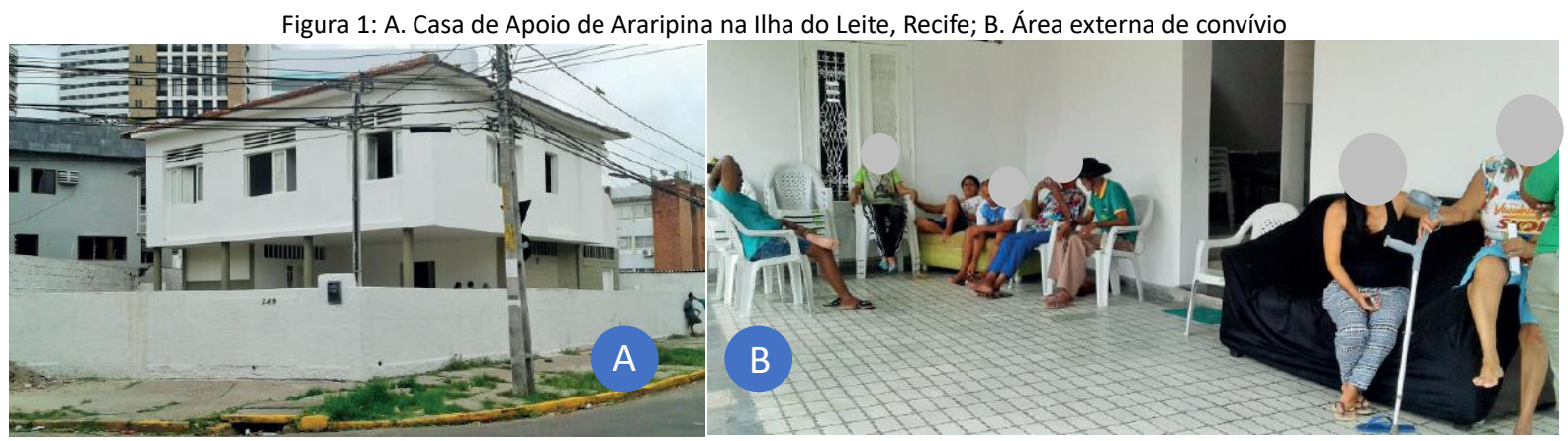

Fonte: Autores, 2018. 


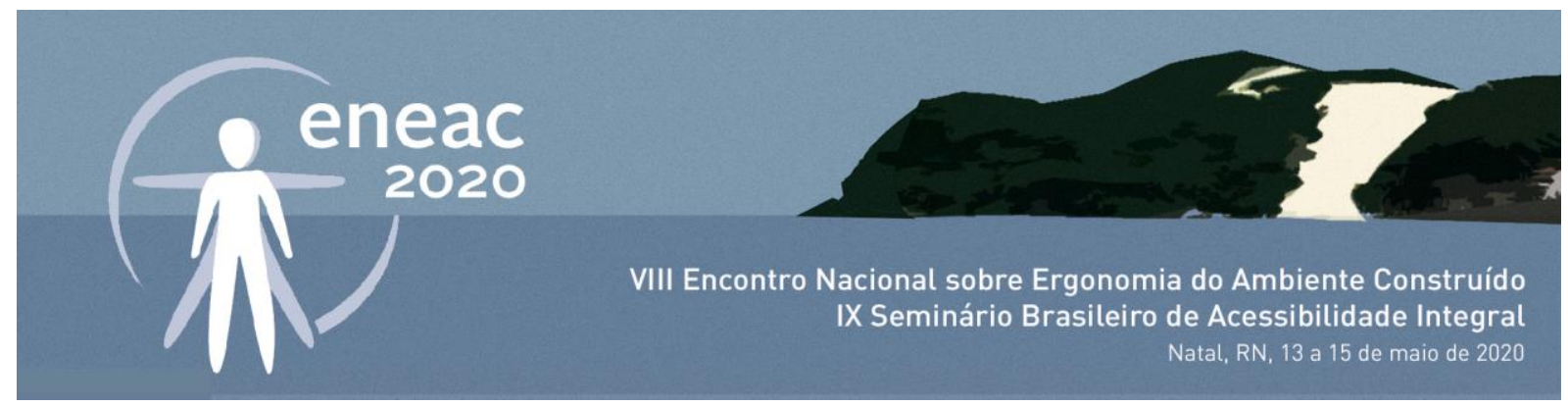

Outro ponto marcante a ser repensado é o fato da área externa ser muito pequena e utilizada para alimentação. Nas horas ociosas ficam poucas pessoas e algumas se deslocam para a praça Dom Bosco defronte a casa que tem melhores locais de permanência e movimento (Figura 1B).

\section{Análise da Configuração do Ambiente Construído}

Nas visitas realizadas ao objeto de estudo foi aplicada a ferramente Walkthrough utilizada para obter os dados positivos e negativos acerca da configuração física do ambiente. É a primeira técnica utilizada no método proposto, após o levantamento geral dos dados.

A seguir, são identificados os problemas de conforto, fluxo, layout e dimensionamento nas plantas baixas elaboradas da casa de apoio e imagens tiradas pelas autoras. Essas dificuldades afetam a qualidade do espaço disponibilizado aos pacientes tornando sua estadia desprazerosa (Figuras 2 e 3 ).

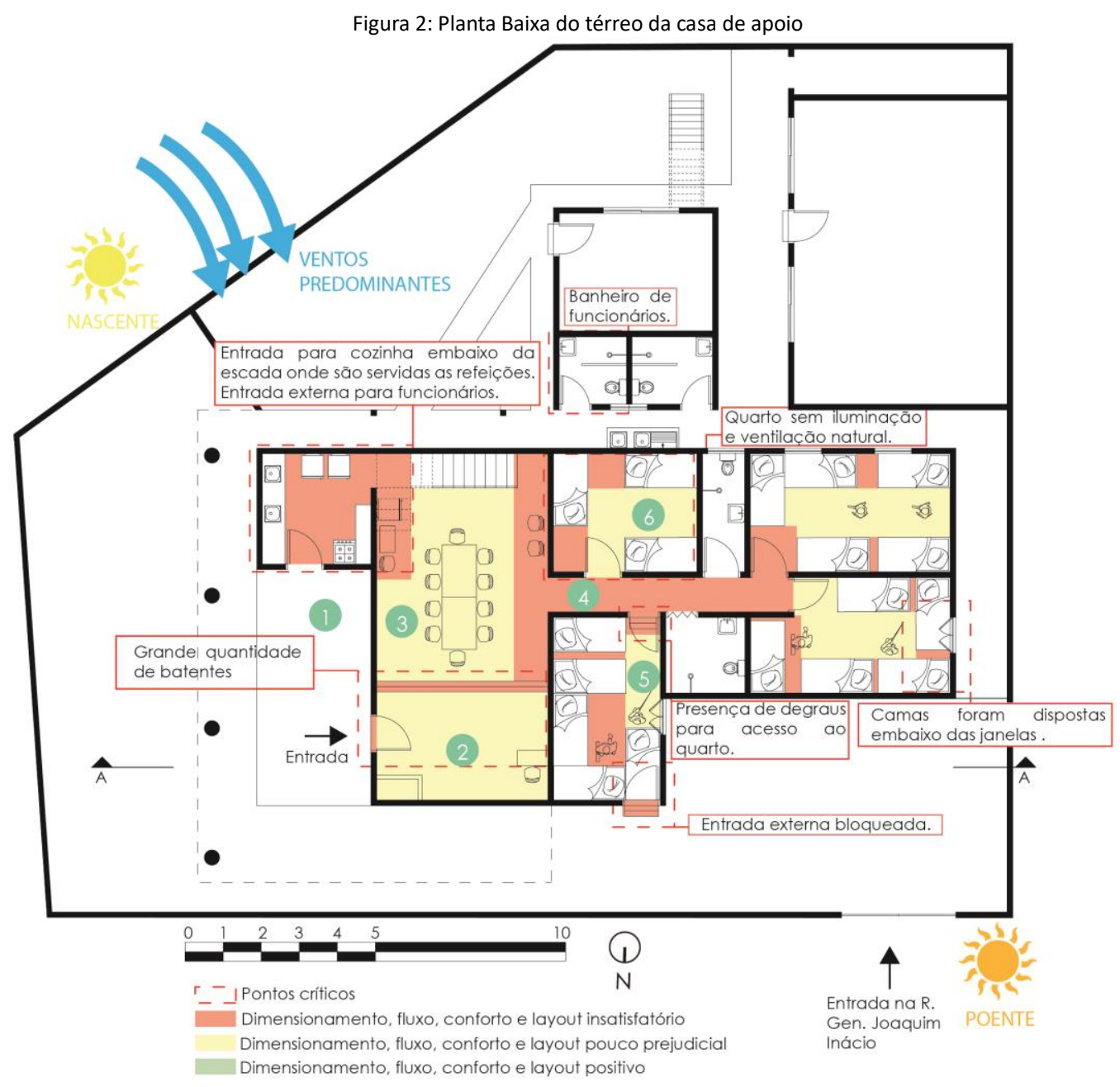

Fonte: Autores, 2019. 

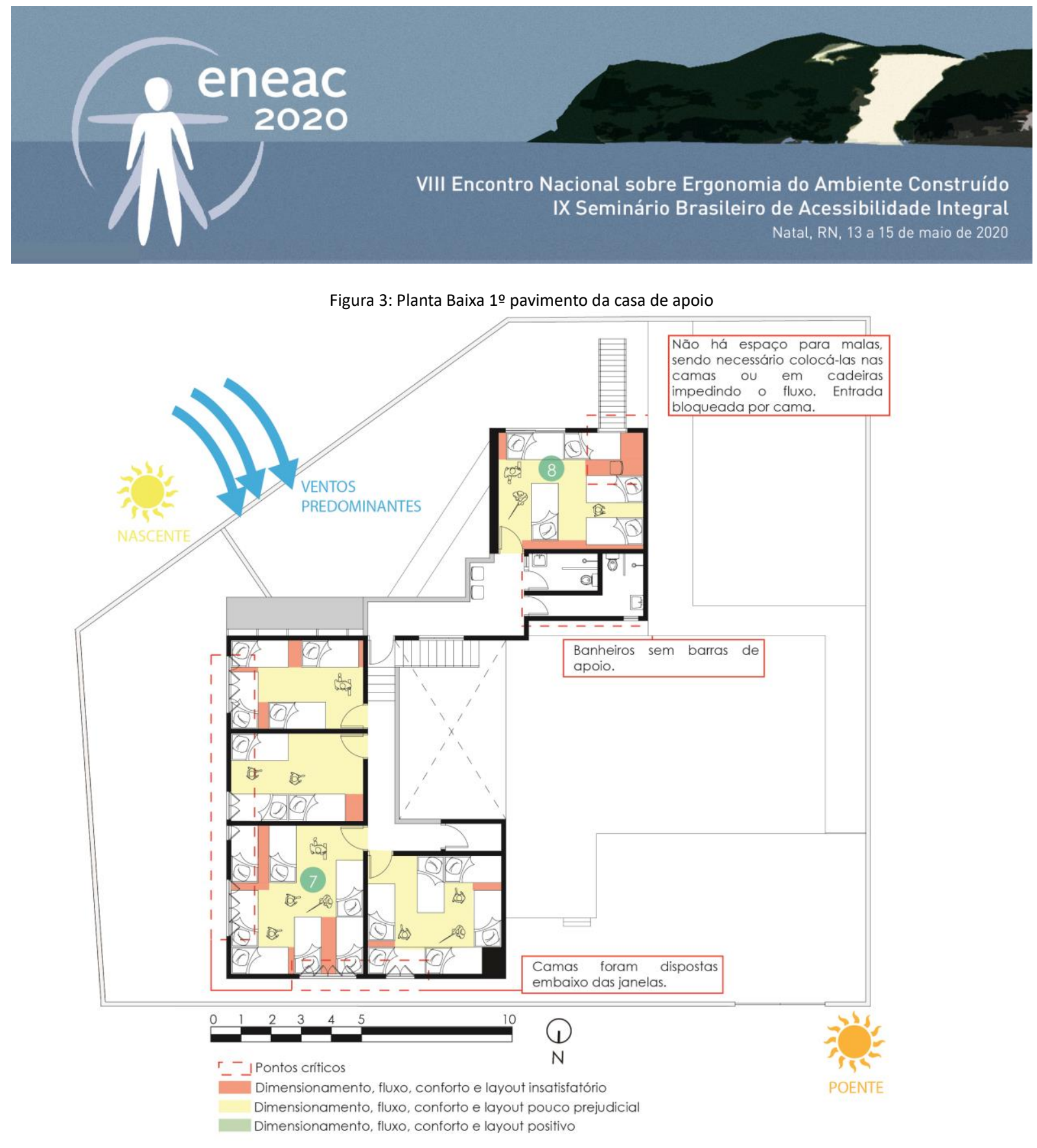

Fonte: Autores, 2019.

Conforme a figura 1B ilustra, a área externa possui maior uso em relação aos outros cômodos por ser um ambiente de convívio, porém, não possui layout adequado, sendo dispostas apenas cadeiras de plástico e dois sofás pequenos, acarretando a falta de conforto. Durante as refeições os usuários se distribuem em cadeiras de plástico pois não há espaço suficiente na sala de jantar. Há uma grande movimentação de pessoas entre o pátio, a sala de jantar e os quartos para o uso dos banheiros localizados no térreo. O cheiro de comida é constante por causa da cozinha próxima a estes ambientes. Não há rampas de acesso já que é um ambiente constituído de muitos batentes, prejudicando a todos, principalmente os que usam muletas ou cadeiras de rodas. Como pode ser visto na figura $4 \mathrm{~A}$, a recepção é um ambiente pequeno e visível a todos que também serve de apoio aos pacientes durante as refeições.

De acordo com a figura 4B, na sala de jantar não há espaço suficiente na mesa para que todos os usuários possam alimentar-se de forma confortável, necessitando que muitos se distribuam em outras áreas da casa. Ainda assim, pode-se visualizar na imagem o acesso para a cozinha que acontece por uma abertura escondida embaixo da escada, prejudicada por uma geladeira e um 


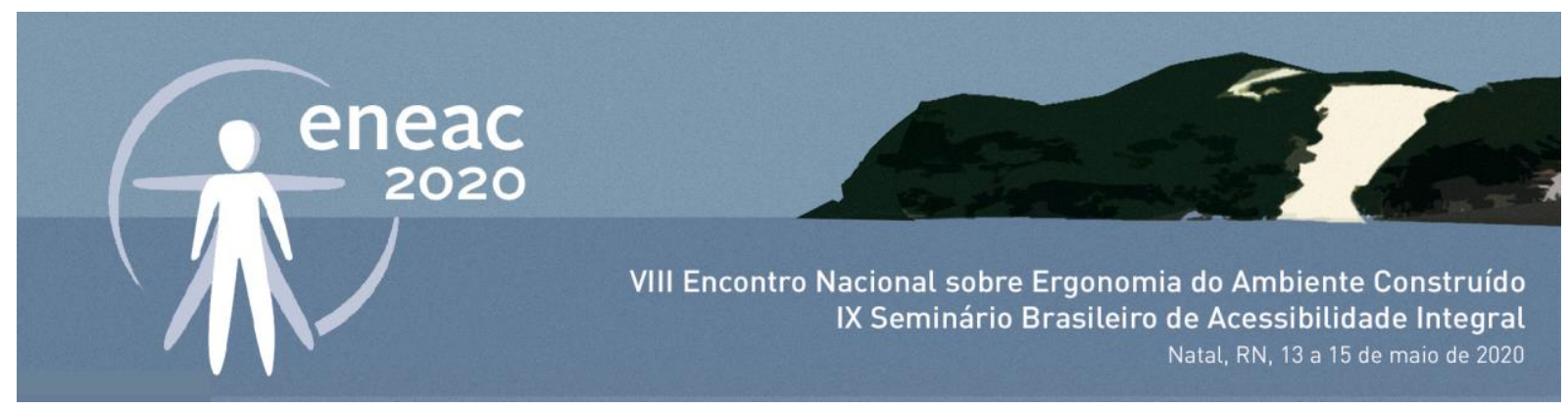

bebedouro que obstruem ainda mais a passagem dos funcionários e a fila formada para os indivíduos receberem as refeições. Há outro acesso para a cozinha localizada na área externa, contudo está sempre fechada para evitar o fluxo de pessoas dentro da mesma, já que a entrada é restrita apenas aos funcionários. Desta maneira, a cozinha é um ambiente fechado, muito escura e pequena, mas apesar do ambiente confuso, há harmonia entre os funcionários.

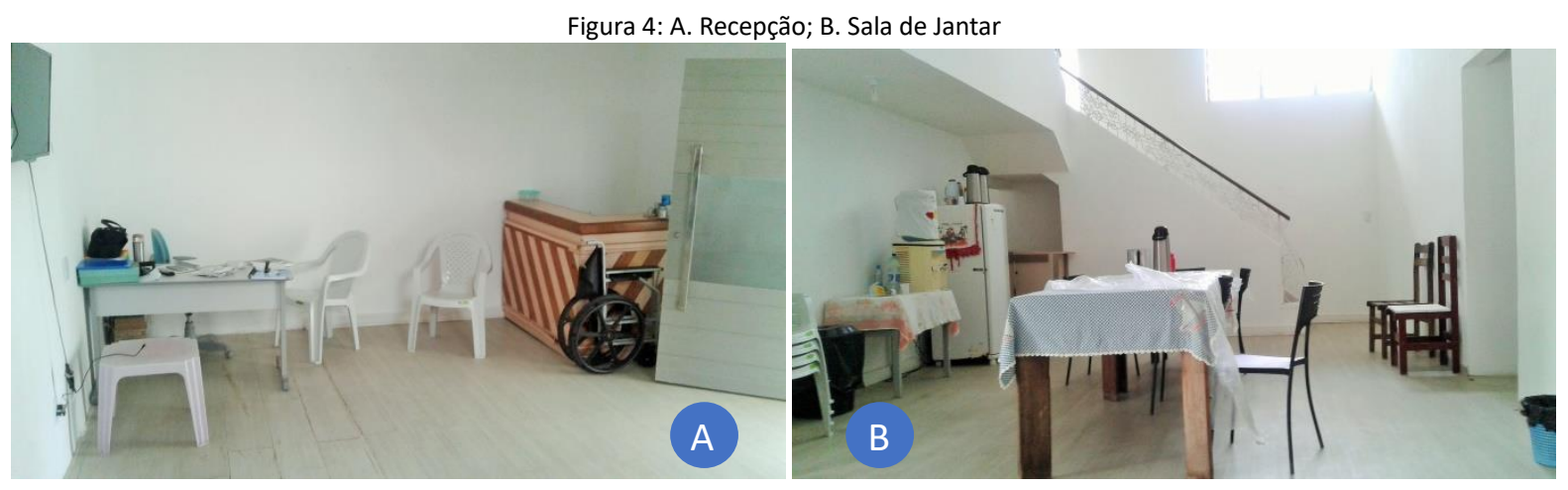

Fonte: Autores, 2018.

Nas plantas baixas do térreo e primeiro pavimento é possível verificar como as áreas de circulação são estreitas. As paredes totalmente brancas não possuem atrativos como desenhos, quadros ou espaços coloridos que alegrem o ambiente.

Segundo a imagem 5A, a maioria dos quartos possuem uma boa iluminação natural, todavia as janelas estão dispostas de maneira inadequada, ficando quando abertas em cima da cabeça do usuário, podendo causar acidentes. Na figura 5B o quarto fotografado não possui iluminação e ventilação natural, deixando o ambiente escuro e insalubre. Como pode ser visto nas imagens, nenhum deles há venezianas para que os pacientes que precisam deitar durante o dia possam ter mais conforto sem que o sol fique refletindo em seus rostos, necessitando da proteção de lençóis ou da própria mão. Os usuários possuem também dificuldade de locomoção entre as camas devido a falta de espaço adequado para circulação, ocasionando o incômodo de ter que ultrapassar malas espalhadas no chão ou esbarrar em outras pessoas. Outro ponto marcante anallisado nas imagens é a falta de privacidade que os usuários possuem, visto que são muitas pessoas instaladas no mesmo quarto e não há onde guardar suas bagagens.

Assim como foi observado nas imagens e nas plantas baixas, a casa de apoio não propicia corretamente aos seus pacientes uma acolhida direcionada a situação de fragilidade que vivem os que a frequentam. Um paciente que fez quimioterapia por exemplo, carece de um conforto diferenciado; são muitas pessoas, cada uma com um problema distinto, muita gente para atender e cada um com um desafio para enfrentar. 


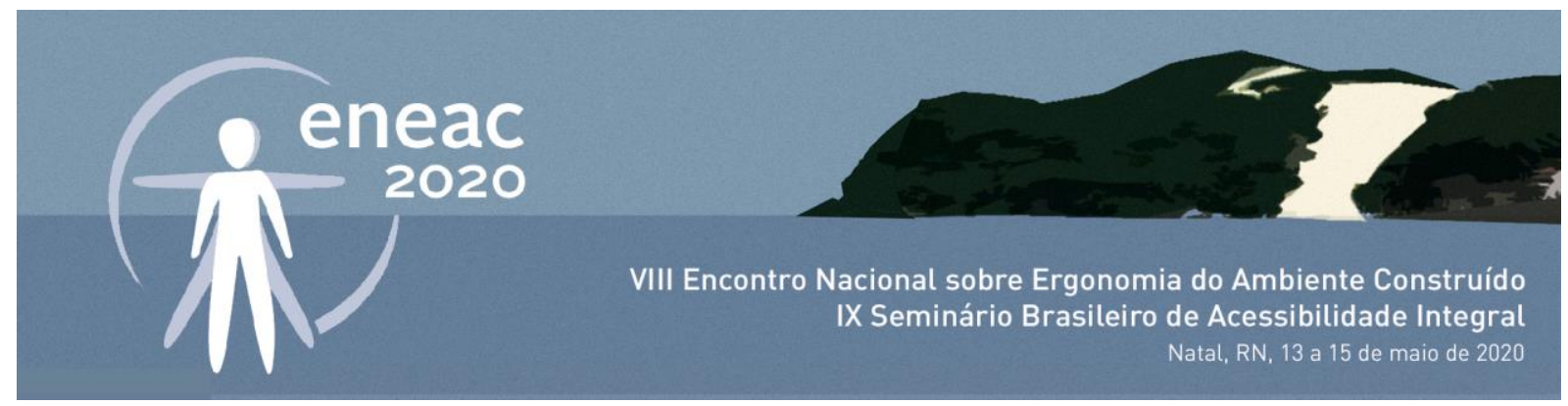

Figura 5: A. Quarto dos homens localizado no 1ํ pavto.; B. Quarto das mulheres localizado no térreo

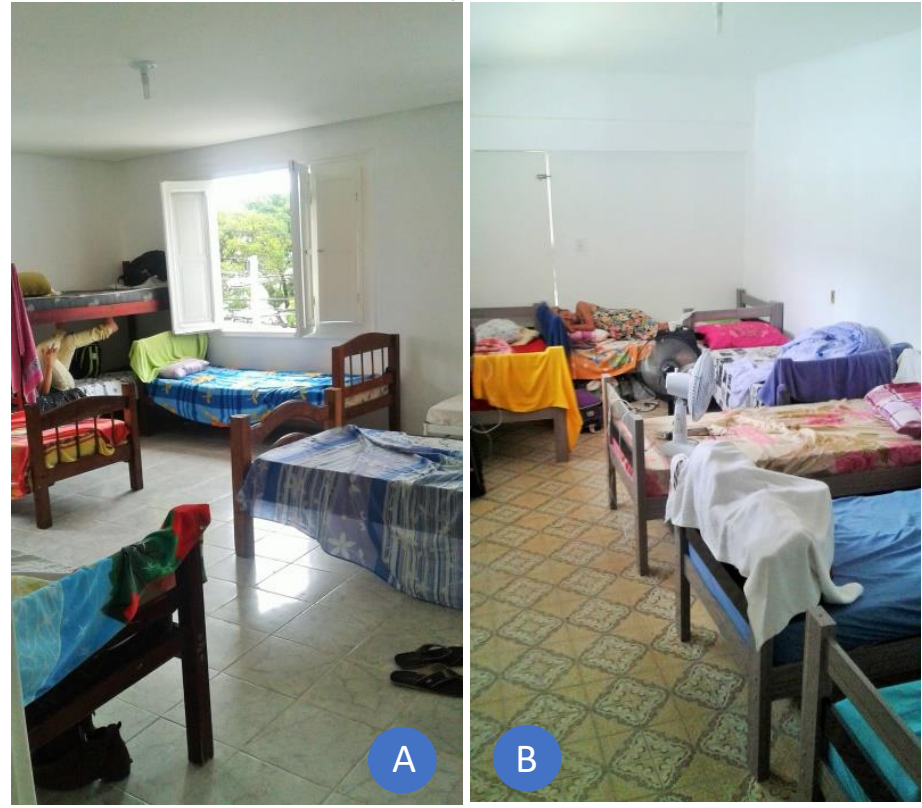

Fonte: Autores, 2018.

A cor das paredes se comparam aos dos hospitais, não tendo um colorido para propiciar alegria. Não possui acessibilidade para todos os tipos de pessoas devido aos desníveis entre os ambientes (Figura 6) e os banheiros não têm barras de apoio. Enfim, muita coisa falta para receber com respeito, dignidade e humanização essas pessoas que precisam de suporte social.

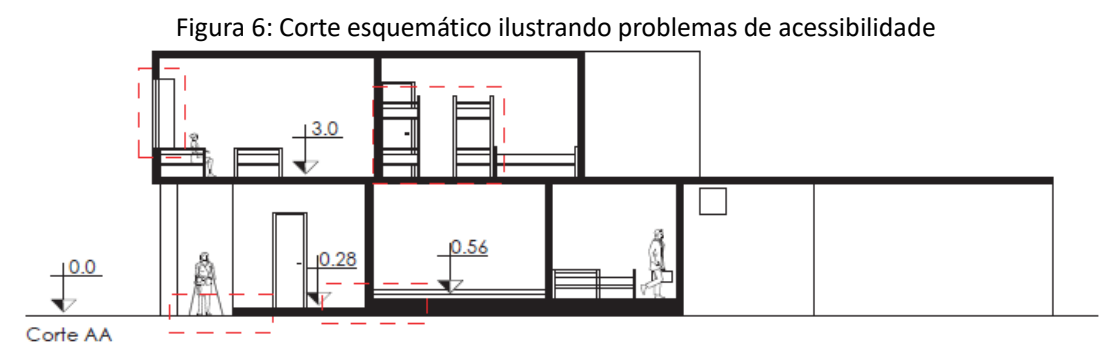

Fonte: Autores, 2019.

\section{Análise da Tarefa}

Através da aplicação da ferramenta analisada no tópico acima, estuda-se quais pontos fundamentais devem ser melhorados ou eliminados. Desta forma, são feitos estudos de fluxos realizados pelos usuários, os deslocamentos desnecessários, o cruzamento de fluxos para que o ambiente proposto possua maior eficiência e quais atividades são feitas, destacando como são realizadas e se o ambiente facilita ou dificulta o cumprimento das tarefas.

Como foi apontado anteriormente, a falta de organização espacial das residências alugadas que recebem os pacientes e seus familiares são adaptações que possuem diversos problemas de conforto, dimensionamento, fluxos, acessibilidade e layout. Outro ponto recorrente ocasionado por essas adaptações são os usos definidos de acordo com que a casa oferece, e nem sempre são feitas as melhorias necessárias para que os usuários sintam-se protegidos. A casa de apoio possibilita um 


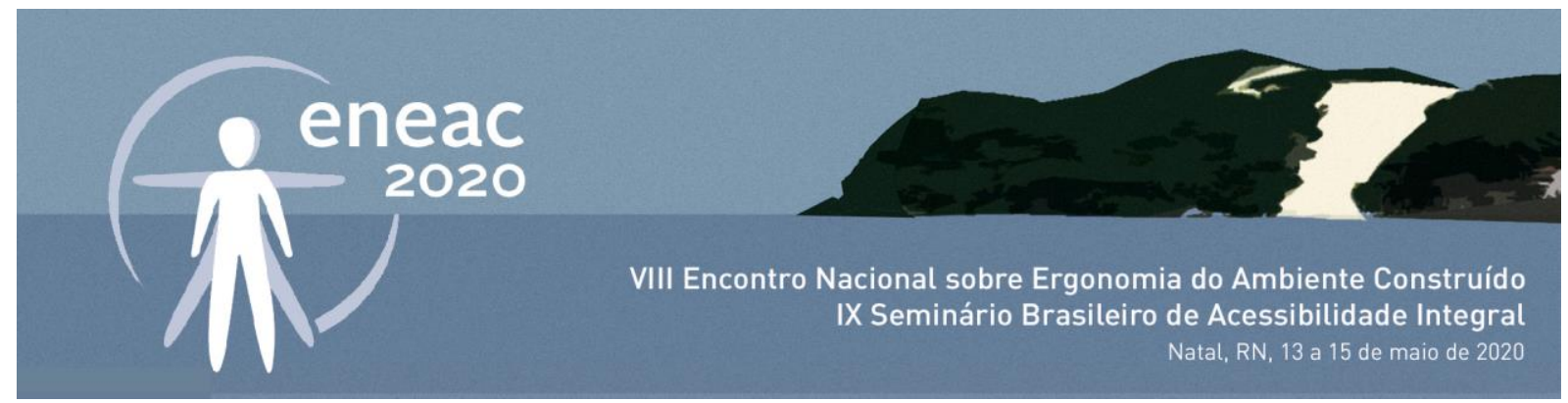

programa mínimo, ilustrado na figura 7, quanto a setorização dos usos em: área social (sala, recepção e área externa), serviço (cozinha e área de serviço) e íntima (quartos e banheiros).

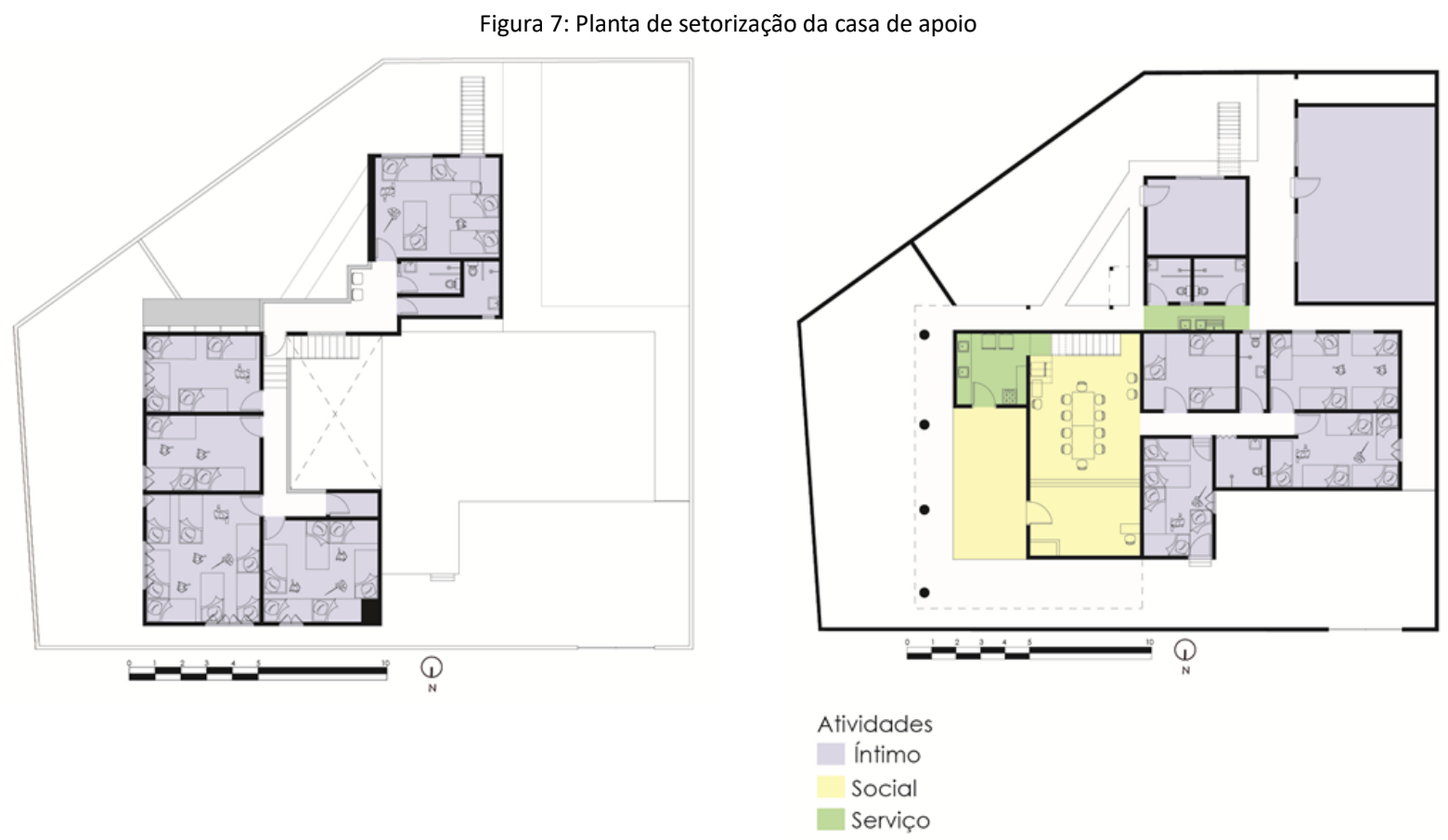

Fonte: Autores, 2019.

Analisa-se a partir das plantas baixas e visitas ao local, os usos definidos para cada ambiente da casa, sendo destacados principalmente a distribuição e insuficiência para acomodar a excessiva quantidade de mobiliário por cômodo, influenciando a sobreposição de atividades, a falta de privacidade e a dificuldade de acomodação. A figura 8 mostra as diferentes atividades presentes no ambiente da casa de apoio, descritas conforme legenda.

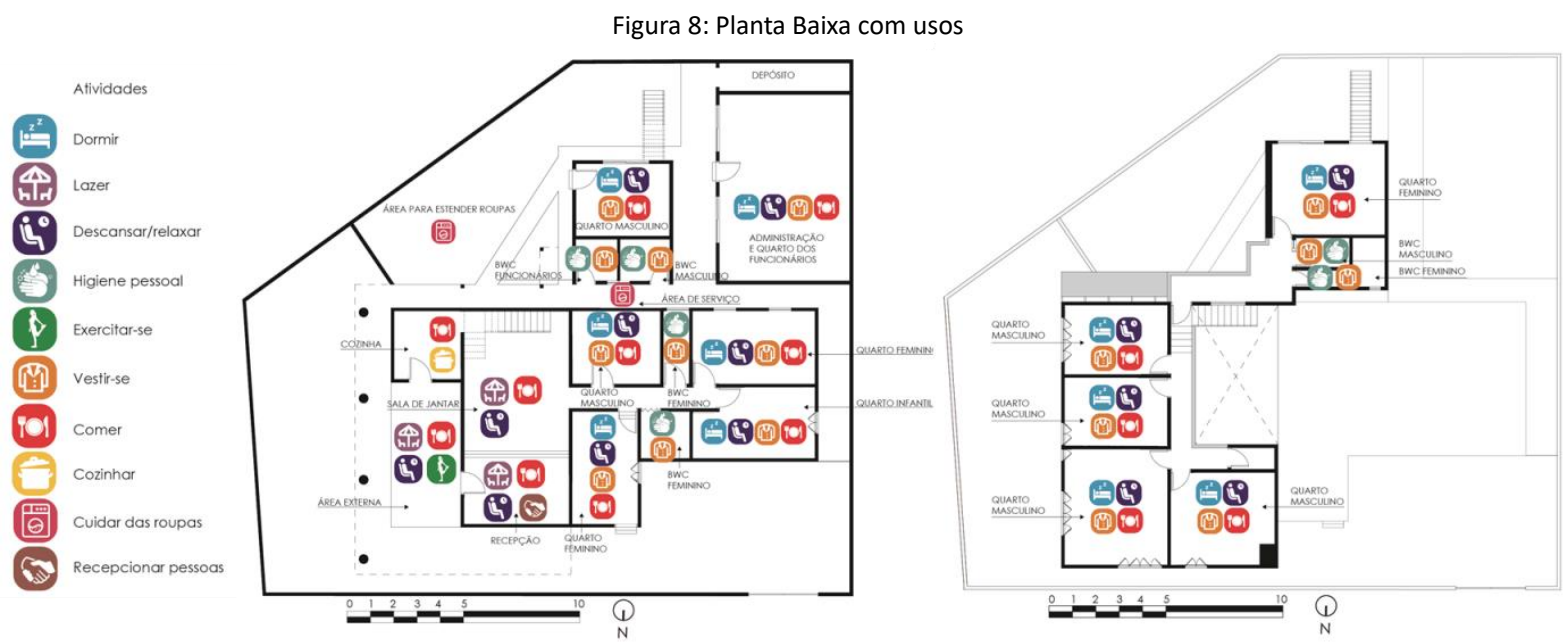

Fonte: Autores, 2019. 


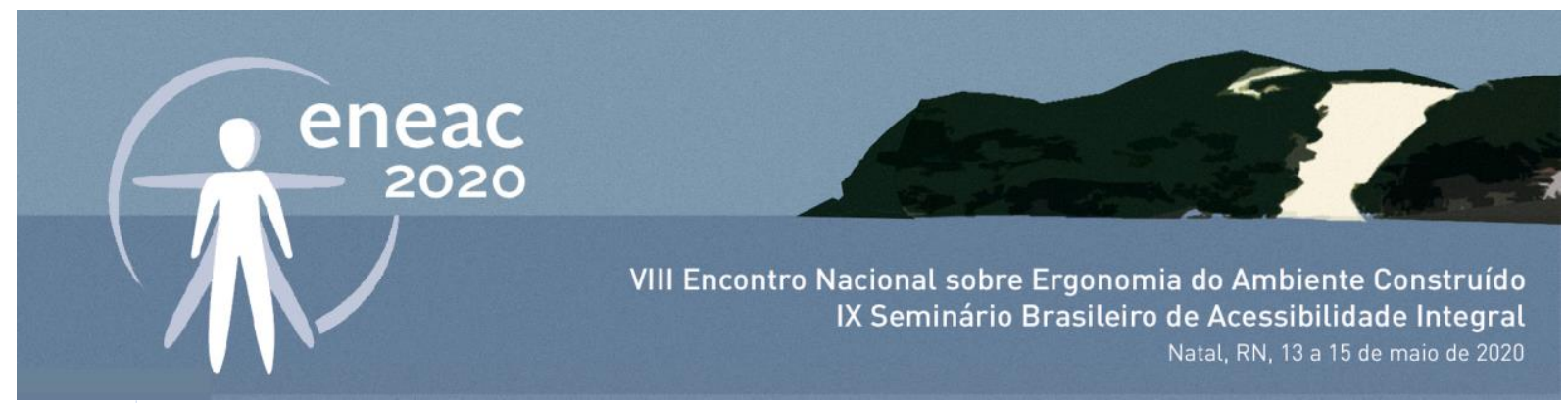

Essas atividades são realizadas de maneiras diferentes, de acordo com o que os usuários definem como viável, cada um tem sua maneira de exercê-las, dependem também do que o ambiente proporciona. No entanto, foi observado que o movimento é bastante acentuado nos banheiros e quartos femininos, localizados no térreo e primeiro pavimento, por estarem próximos e facilitarem o desenvolvimento das atividades propostas, mas para os quartos masculinos, os usuários precisam locomover-se para os banheiros que se encontram no primeiro pavimento ou nos fundos da casa, aumentando a movimentação na escada. O deslocamento para a área de serviço e os banheiros de trás causam a passagem frequente de pessoas pela sala, recepção e área externa, assim como o banheiro dos funcionários que encontra-se também nos fundos da edificação, reforçando ainda mais esse fluxo. A área social possui espaços sub-dimensionados para os usos, sendo os ambientes com maior número de pessoas, especialmente por servirem de apoio nos horários das refeições. A cozinha permite o desenvolvimento das atividades, contudo é um ambiente pequeno e o local de distribuição das refeições é estreito, acarretando o agrupamento dos fluxos.

A planta demonstra inflexibilidade na concentração de funções, que são melhores desenvolvidas quando próximas, tornando a realização das atividades mais complicadas e gerando intensidade dos fluxos.

\section{Análise da Percepção do Usuário}

Foi possível identificar através de entrevistas como os usuários percebem e utilizam os espaços, suas satisfações e insatisfações com relação à moradia, assim como as deficiências e potencialidades da atual casa em relação aos aspectos funcionais, espaciais e ambientais. Com base no conteúdo destas entrevistas, o quadro 1 apresenta uma síntese dos principais problemas e potencialidades identificados.

Quadro 1: Síntese dos problemas x potencialidades identificados na casa de apoio

\begin{tabular}{|c|c|}
\hline PROBLEMAS & POTENCIALIDADES \\
\hline $\begin{array}{l}\text { A maioria dos quartos estão localizados no primeiro } \\
\text { pavimento }\end{array}$ & Área de lazer conectada com a natureza \\
\hline Quartos quentes, precisando de mais ventiladores & Ambientes coloridos, com quadros \\
\hline $\begin{array}{c}\text { Quartos pequenos, sem espaço para as camas e } \\
\text { circulação }\end{array}$ & Espaço para pintura \\
\hline Ausência de armários para guardar as malas & Cozinha compartilhada \\
\hline Banheiros sem barras de apoio & Acessibilidade \\
\hline Presença de batentes e escada & Espaços lúdicos \\
\hline Cozinha fechada para os usuários & Acompanhamento com psicólogo e assistente social \\
\hline \multicolumn{2}{|l|}{ Falta de mesas para refeições ou lazer } \\
\hline \multicolumn{2}{|l|}{ Paredes totalmente brancas } \\
\hline Piso inadequado & \\
\hline
\end{tabular}




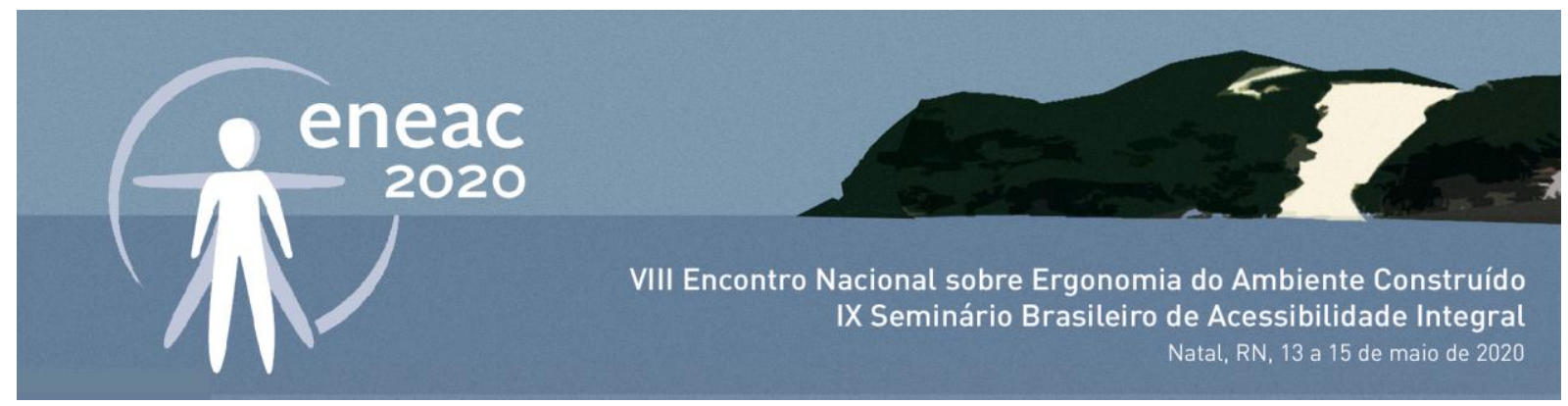

\section{Diagnóstico}

Baseado nos dados colhidos sobre a estrutura física do ambiente a partir da observação do pesquisador e dos usuários, destacando suas necessidades, obteve-se os resultados da avaliação. Os problemas identificados foram:

- Ausência de copa perto dos quartos para preparo de medicamentos e refeições rápidas;

- Distribuição desordenada do mobiliário;

- Falta de conforto e privacidade nos quartos;

- Mesa fora de proporção, sem lugares para todos os usuários;

- Espaços livres mal utilizados causando desordem na circulação dos ambientes;

- Não há acessibilidade ao interior da edificação;

- Inexistência de armários para malas e pertences pessoais;

- Janelas são abertas para o interior, prejudicando as atividades;

- Carência de mobiliário adequado para os momentos de lazer e descanso.

Percebe-se que a casa de apoio também possui pontos positivos que devem ser preservados na elaboração das diretrizes, são eles:

- A presença de um terraço de convivência e de um espaço aberto para estimular o contato social e com a natureza, o descanso e a realização de exercícios;

- O quarto destinado para crianças;

- A separação de quartos e banheiros quanto ao sexo;

- O espaço destinado a lavagem de roupas, que apesar de distante dos quartos, apresenta espaço aberto para a secagem das roupas.

\section{Diretrizes Projetuais}

As diretrizes para o projeto de casas de apoio como a apresentada neste artigo foram estabelecidas a partir da conceituação temática e do estudo de caso, considerando também os desejos dos pacientes. É necessária essa análise para criar um projeto arquitetônico que atenda as necessidades da população enquanto estão longe de suas casas.

Quanto ao projeto, propõe-se:

a. A copa e o refeitório correspondem ao coração da edificação e para criar um ambiente agradável de convivência pode ser aberto e voltado para um pátio central com vegetação.

b. A escala da edificação deve basear-se na residencial com térreo e 1ํ pavimento.

c. Quartos abertos para o jardim criando ambientes de contemplação, com portas dobráveis, com folhas em venezianas móveis para garantir a privacidade.

d. Criar opções de controle para propiciar a ventilação cruzada e reduzir o uso do ar condicionado (Figura 9). 


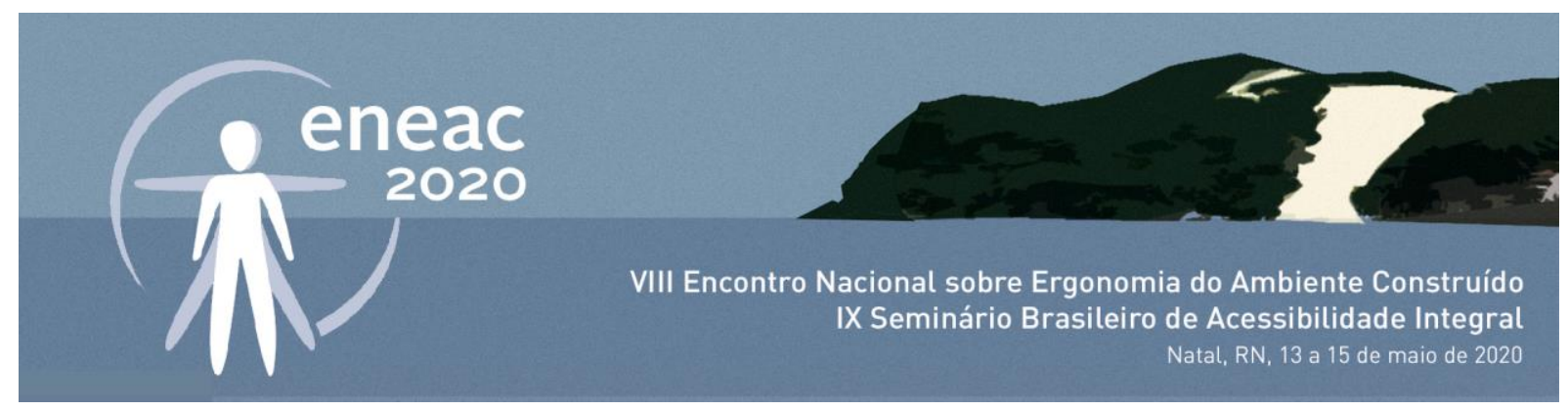

Figura 9: Janela com opção de controle da iluminação e ventilação

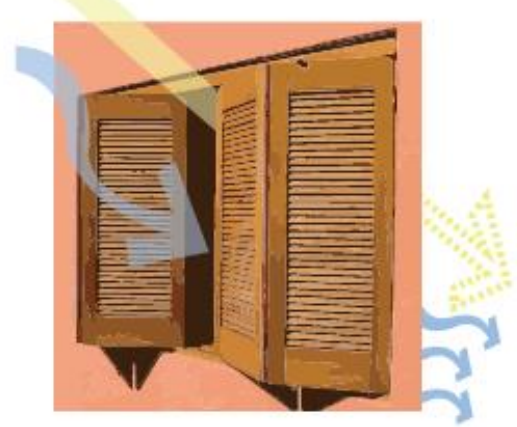

Fonte: Autores, 2019.

e. Estabelecer a relação interior/exterior, a natureza adentra no edifício abafando os sons indesejados e proporcionando calmaria.

f. Ambientes internos e a circulação circundando um pátio central como estratégia que minimize ambientes isolados, corredores estreitos e longos e permita a entrada de iluminação natural (Figura 10).

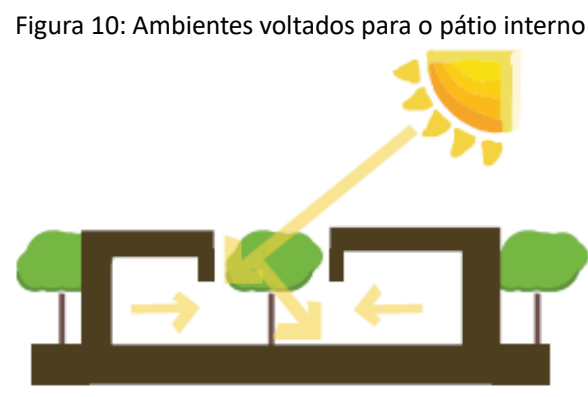

Fonte: Autores, 2019.

g. Uso de cores neutras mas que alguns ambientes como corredores e áreas de convivência sejam coloridos.

Quanto ao programa e zoneamento, propõe-se:

h. Criação de ambientes de uso coletivo dispondo de atividades que possam ser realizadas durante o dia para distração e divertimento, por exemplo, salas de oficina e leitura.

i. Os ambientes de uso íntimo devem ficar longe do acesso principal, reservando o espaço livre da poluição sonora para o descanso.

j. Disposição de poucas camas por quarto, sugere-se o número 3, com armários individuais, poltronas de descanso e mesa de apoio para alimentação, estudo ou trabalho (Figura 11). 

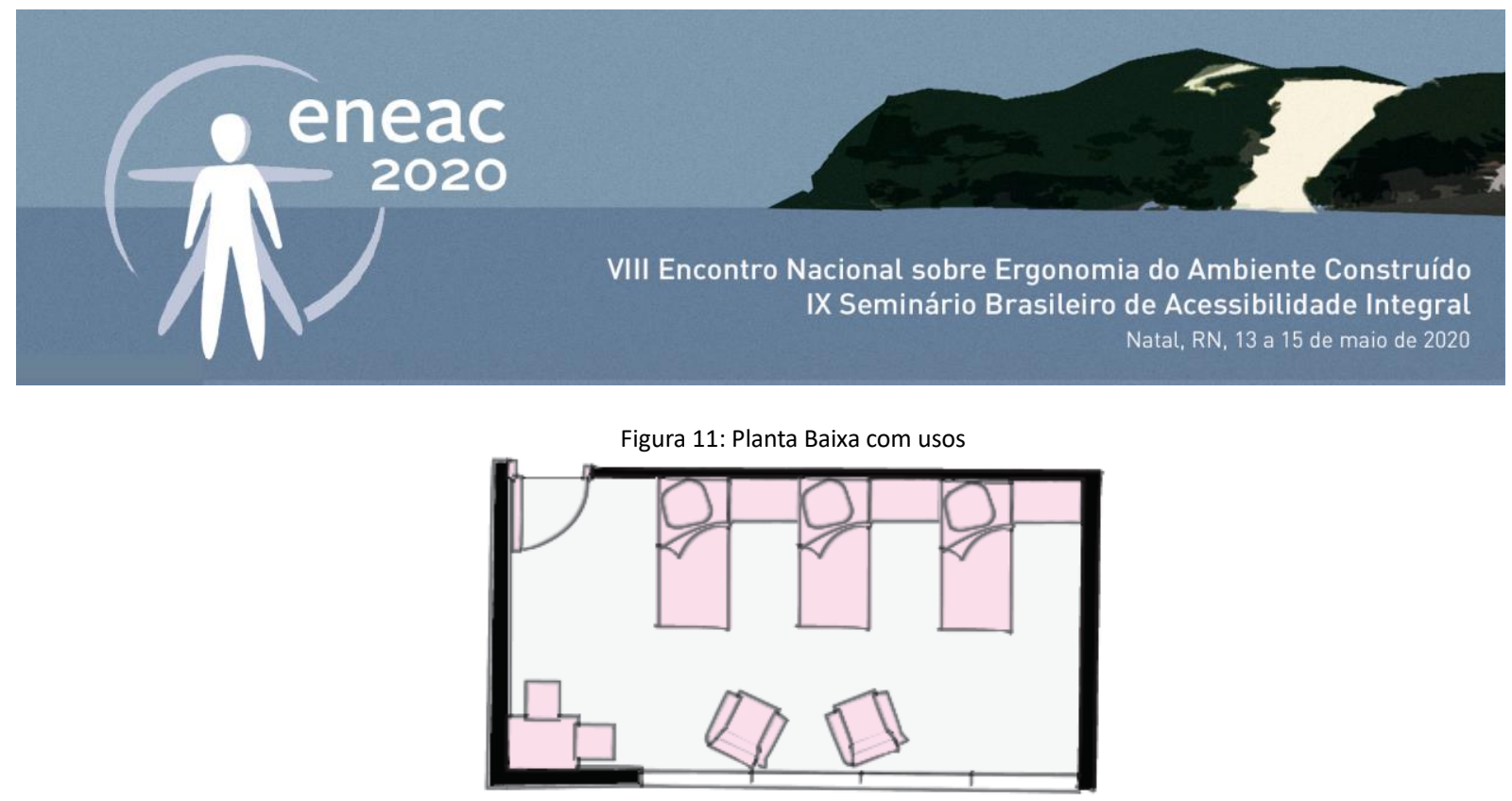

Fonte: Autores, 2019

\section{CONSIDERAÇÕES FINAIS}

O presente estudo caracterizou a realidade de uma casa de apoio localizada na cidade do Recife (PE) com base no uso e percepção do usuário. Traçou o perfil dos usuários da casa e apontou os aspectos positivos e negativos do ambiente construído. Analisando os dados apresentados, foi possível verificar muitas questões que expressam as dificuldades dos pacientes que dela usufruem, quanto a questão da acomodação de forma satisfatória.

Neste contexto, diretrizes projetuais foram sugeridas visando a melhoria da qualidade de vida dos pacientes e seus acompanhantes, focando nos espaços apropriados a estes que se encontram em estado de vulnerabilidade, precisando de amparo, acompanhamento e assistência humanizada. Esta elaboração não tem a intenção de definir padrões para casas de apoio, mas sim contribuir com sugestões para amenizar os problemas da falta de áreas de lazer, privacidade, acessiblidade, etc, priorizando os aspectos positivos de conforto ambiental que atuem como aliados no processo de cura e recuperação do paciente por meio da humanização e do espaço físico.

Uma casa de apoio bem arquitetada, apresenta-se como um local benéfico para a população que dela usufruem, fazendo com que sintam-se inseridas em algo maior, priorizando a socialização do ser humano mas mantendo a sua individualidade.

\section{REFERÊNCIAS}

BRASIL. Ministério da Saúde, Secretaria de Políticas de Saúde. Tratamento Fora do Domicílio. Brasília: Editora do Ministério da Saúde, 1999.

BRASIL. Ministério da Saúde, Secretaria de Atenção à Saúde. Cartilha de Ambiência. 2ed. Brasilia: Editora do Ministério da Saúde, 2010.

FALCÃO, C.; SOARES, M. Ergonomia e análise multidisciplinar do ambiente construído. Anais do III Encontro Nacional de Ergonomia do Ambiente Construído e IV Seminário Brasileiro de Acessibilidade Integral - ENEAC. P. 1-7, 2011.

FERREIRA, P; WAKIUCHI, J; BALDISSERA, V.; SALES, C. Sentimentos existenciais expressos por usuários da casa de apoio para pessoas com câncer. Esc. Anna Nery Revista de Enfermagem 19(1): 66-72, JAN-MAR 2015.

GOMES, L.; FELIPE, M.; FALCÃO, C. Avaliação Pós-Ocupação e Projeto Participativo: Estudo de caso de uma cozinha residencial unifamiliar. In: Simpósio Brasileiro de Qualidade do Projeto no Ambiente Construído. João Pessoa - PB: ANTAC, 2017.

MELO, R.; SAMPAIO, M. Casas de apoio: inserção e contribuilçoes do assistente social no terceiro setor. Revista Científica da Faminas 9(2):115-144, 2013. 


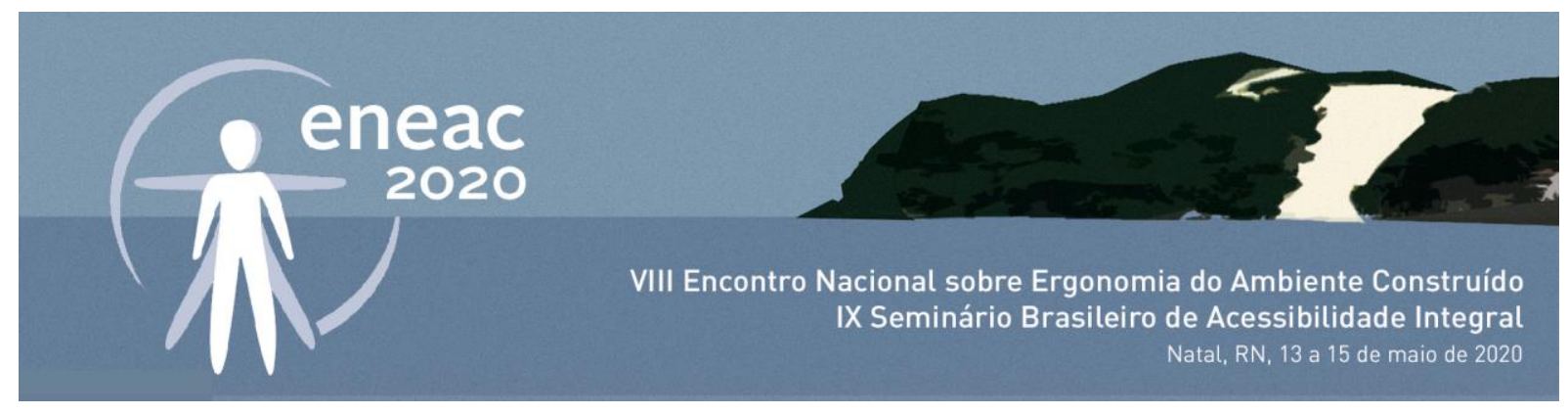

SOLIS, D.; FUÃO, F. Derrida e Arquitetura. 1ed. Rio de Janeiro: Editora Eduerj, 2014. Diponível em http://www.eduerj.uerj.br/internaBooks/internaBooks.php?id=107. Acesso em Janeiro de 2020. 